\title{
COMUNICAÇÃO
}

\section{O SISTEMA ÚNICO DE SAÚDE: UMA OPORTUNIDADE ÚNICA}

\author{
Vicente Amato Neto e Jacyr Pasternak
}

Somos estudiosos e interessados em saúde pública e na biologia dos muitos e numerosos microrganismos que co-habitam e infernizam a vida dos muitos que moram em países tropicais. Somos, muitos, homens de laboratório ou epidemiologistas e frequentemente desligamo-nos de problemas mais prosaicos e administrativos. Somos, no entanto, todos cidadãos e precisamos não só saber o que se passa na organização desta nação e do sistema de atendimento médico público, mas também participar e dar nossa opinião. Seguramente, se não o fizermos vamos ser surpreendidos com decisões prejudiciais para nós como pesquisadores e para o Brasil de um modo geral, convindo frisar que o momento é agora, se não estivermos ligeiramente atrasados. Em 1988, a "Constituição Cidadã" deu direitos aos brasileiros que no papel os equiparam aos habitantes das regiões mais desenvolvidas. Assim, todo brasileiro tem direitoà cobertura completa dos seus problemas de saúde, ao acesso a todos os níveis do sistema de atendimento e à medicação, que faz parte evidentemente do tratamento. A mesma Constituição, no entanto, não definiu com precisão a fonte de pagamento e isso deixa o Sistema Único de Saúde (SUS), nela consagrado, meio no ar. Se assim não fosse estaríamos todos muito satisfeitos. Vários dos dramas que acompanhamos a propósito dos nossos pacientes com doenças endêmicas originam-se do fato de não serem disponíveis diversos fármacos apropriados, por razões comerciais. Empresas do primeiro mundo não têm, comumente, interesse em produzir remédios usados exclusivamente no terceiro, por gente paupérima, sem condições de bancá-los, implicando isso em cobrar de Governos outrossim pobres e peritos em promover calotes, tornando os fabricantes cansados de saber se não quiserem pagar é difícil obrigá-los. Não há como pedir falência de Governos, o que é uma pena, pois se fosse viável sobrariam poucos na faixa sul do

Faculdade de Medicina da Universidade de São Paulo, São Paulo, SP. mundo. Agora existe obrigação de fornecer tais medicamentos, sem que a Constituição tenha indicado como e isso precisa ser discutido. Não temos indústria farmacêutica nacional com capacidade de fazer tais produtos e a determinação constitucional, se seguida a contento, pode constituir o ponto de partida para formar setor genuinamente brasileiro, onde suceda, com compostura de não apenas maquiar, evitando-se assim criticável procedimento, tão reiterado nestas bandas.

Igualmente, dentro de um sistema unificado o papel dos laboratórios de saúde pública é extremamente relevante. Ações integradas precisam de dados de vigilâncias sanitária e epidemiológica, não se fazendo nem uma coisa nem outra sem bons órgãos dessa natureza. Mais uma vez, tem lugar a oportunidade de equipar a devida importância aos nossos, que não recebem o devido valor na consciência nacional, exatamente porque até agora inexistia diretiva conveniente, devidamente integrada. Com o SUS é possivel planejar e manter algumas das nossas conquistas na área de saúde pública; afinal vacinação das crianças de São Paulo não está em situação muito diferente da vigente em vários Estados norteamericanos. Vale lembrar ainda que ficará factivel aferir quais são as nevessidades e a importância das várias doenças que nos afligem. Se existisse um SUS funcionante acreditamos que a febre purpúrica brasileira teria suas etiologia e epidemiologia delineadas mais depressa; o fato de termos chegado lá em tempo bem razoável, se bem que utilizando apoio dos "Center for Disease Control" (CDC), sugere que contamos com pessoal e capacidade técnica para efetuar tal tipo de estudo. Falta integrar os laboratórios de saúde pública no contexto da realidade de um sistema único, integrado, hierarquizado e descentralizado nas ações de execução das manobras, sempre com direção. Esse ponto é crítico, uma vez afigura-se indispensável diretriz lógica, baseada em dados científicos oriundos dos nossos referidos laboratórios.

Alguns sócios da Sociedade Brasileira de Medicina Tropical exercem atividades em hospitais 
universitários. No SUS essas instituições costumam acolher grandes complexidades assistenciais e configuram indubitavelmente elementos críticos do sistema, podendo levar à comunidade o que se aprende academicamente. Cientistas biológicos não podem trancar-se em excelsas torres de marfim nunca, em nenhum país e muito menos no nosso. Todos os que recebem salários advindos de dinheiro orçamentários, governamental, devem ao povo que os paga dedicação e compromisso de serví-lo com algo que lhe seja útil. Pesquisa básica, é claro, merece apreço e atenção; porém, decididamente, investigações devem ter algum embasamento na realidade, se possível propiciando retorno, que não precisa ser rápido. Contudo, os cidadãos que duramente contribuem para o erário são dignos de benefícios pertinentes, para eles mesmos ou, pelo menos, para seus descendentes.

Por isso tudo, fazemos um apelo ao colegas. Sentem, discutam e pensem a respeito da inserção profissional num sistema único de saúde, adespeito do assunto parecer não muito relevante, presentemente, no que fazem. Desenhem cenários, avaliem possibilidades. Muitíssimo importante, conforme, nossa opinião, é examinar de forma transparente o financiamento do processo. Apesar da tradição brasileira de não projetar e de imaginar o Governo como uma infinita fonte de recursos, estamos percebendo que não é assim. Somos favoráveis ao SUS como idéia, imaginando-o algo equalitário, decentee, se bem organizado, eficiente. É viável, até no Brasil, desde que conte com recursos suficientes, não exagerados e desprovidos de luxo. Insistimos: definidos claramente e descentes. Não obstante, como reza um famoso provérbio, "o queé bomé caro, e oque é muito bomé muito caro"., não fugindo disso o sistema de saúde. Do bolo de recursos, impõe-se alocar muito mais à saúde, num contexto em que o plano mostre funcionalidade e utilidade, senão persistirá o círculo vicioso que vemos hoje: já que o sistema não é bom, ninguém quer contribuir para mantê-lo e vai procurar para si e os seus condutas paralelas, que por vezes conseguem ser ainda mais ineficientes e sempre requerem elevados dispêndios. 